\title{
THE TREATMENT OF CONGENITAL GALACTOSAEMIA
}

\author{
BY \\ NORMAN L. JONES and DAVID LEAK \\ From the British Military Hospital, Rinteln, Germany
}

(RECEIVED FOR PUBLICATION JANUARY 23, 1959)

Congenital galactosaemia is now a well recognized inborn error of metabolism and over 45 cases have been recorded (Andersen, 1957; Bennett, 1958). The underlying defect is the absence of the enzyme phospho-galactose uridyl transferase (Isselbacher, 1957), which catalyses the first stage of the conversion of galactose-l-phosphate to glucose; this results in an inability to metabolize galactose, and causes the intolerance to milk which characterizes the condition.

The clinical features of galactosaemia are of varying severity: for example, previously unsuspected cases have been recently discovered in mental defectives (Bergren, Donnell and Kalckar, 1958), while relatives of established cases may have an abnormal galactose tolerance test as the only manifestation of the disease (Holzel and Komrower, 1955). There is a marked contrast between these subjects and the acute form of the disease presenting with jaundice, hepatomegaly, galactosuria and amino-aciduria in the newborn, which, despite improved methods of diagnosis, still carries an appreciable mortality (Cox and Pugh, 1954; Clay and Potter, 1955; Holzel, Komrower and Schwarz 1957; Isselbacher, 1957).

Mason and Turner (1935) first described the successful use of a milk free diet in the treatment of an 11-month-old baby with galactosaemia; at the age of 24 years (though mentally retarded) he was able to tolerate small amounts of galactose (National Institutes of Health, 1957). In view of the recent increase of interest in this condition and the likelihood of its more frequent diagnosis, the purpose of this report is to evaluate the various diets which may be used, and to re-emphasize the necessity of the complete exclusion of lactose from the diet.

\section{Case Report}

C.S., a girl of $8 \mathrm{lb} .8 \mathrm{oz}$, was born after an uneventful pregnancy on February 18,1958 . Three days later she became slightly jaundiced and lethargic and during the following week became increasingly disinterested in feeding at the breast; half cream National Dried Milk was substituted. On March 1, 1958 (twelfth day) she weighed $7 \mathrm{lb} .1 \mathrm{oz}$, and was deeply jaundiced, the liver edge was palpable one inch below the costal margin and the abdomen was distended. She was apyrexial. Haemoglobin was $117 \%$ (17.4 g.), Coombs' test negative. Bilirubin was present in the urine, urobilinogen absent; there was a trace of albumin. Bile pigment was present in the stools. Over the next few days she developed a temperature of $100-101^{\circ} \mathrm{F}$., which responded to empirical treatment with chloramphenicol and streptomycin. The liver increased in size and the serum bilirubin was $20 \mathrm{mg} . / 100 \mathrm{ml}$; thymol turbidity 2 units and alkaline phosphatase 40 King Armstrong units. On March 10 (twenty-first day) examination of the urine showed a reducing substance from which phenyl-lactosazone was formed with phenyl-hydrazine. Paper chromatography later confirmed that this specimen contained galactose and also cystine, 1-tyrosine and 1-leucine among other unidentified amino acids. On this day the half cream milk was replaced by a mixture containing Casilan (Glaxo), dextrose and water. There was a prompt response and after three days the serum bilirubin had fallen to $8 \mathrm{mg}$. $/ 100 \mathrm{ml}$. and the alkaline phosphatase to 25 K.A. units. The urine no longer contained a reducing substance though a trace of protein was still present. The weight had increased to $7 \mathrm{lb}$. $10 \mathrm{oz}$., the abdomen was less distended, and the liver smaller, but the spleen was now palpable. As this mixture was known to contain a small amount of lactose, a diet consisting of malt and soya (Soya Baby Food, Wander) was commenced on March 13 (twenty-fourth day). This was well tolerated at first but increasingly frequent loose stools prevented weight gain, and finally the diet was abandoned because of severe diarrhoea. The Casilan mixture was reintroduced but the diarrhoea continued and treatment with oral crystalloids was necessary to control the dehydration. A recurrence of fever on March 23 (thirtyfourth day) was due to a gluteal abscess which required incision and surgical drainage. On the same day feeding with half-strength L.L. Milk Food (Cow and Gate) was commenced. The food was taken well, but on the first day the infant had two generalized convulsions. The haemoglobin had now fallen to $57 \%(8 \cdot 4 \mathrm{~g}$.) and a small blood transfusion was given. Over the next six weeks, the L.L. Milk Food was well tolerated. However, the liver remained enlarged (two inches below costal margin) and the spleen became more prominent. The serum bilirubin was $1 \mathrm{mg} . / 100 \mathrm{ml}$. and the alkaline phosphatase 


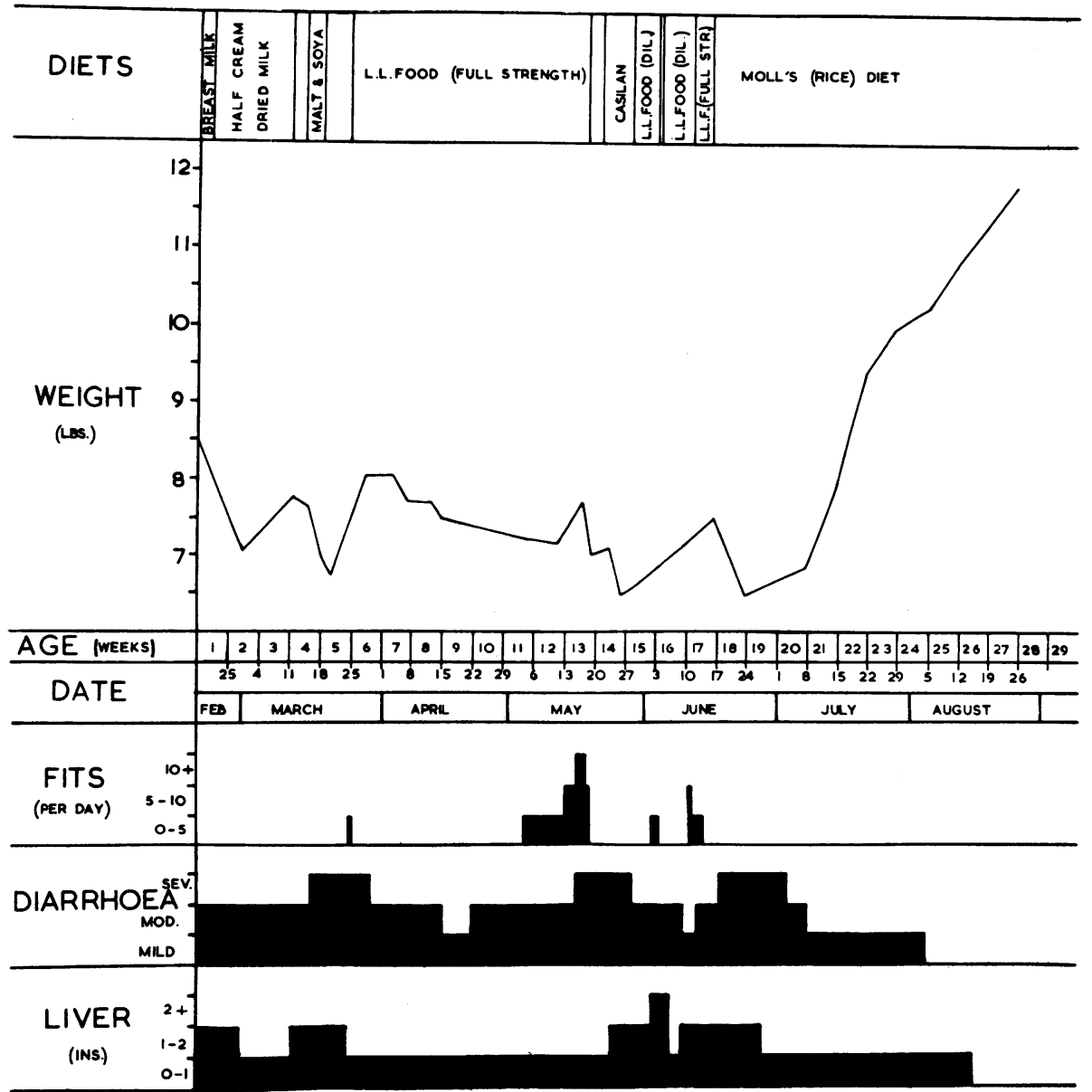

FIG. 1.-Chart illustrating the response to the various diets used. The periods in which no diet is indicated are those when simple dextrose-electrolyte solutions were used, except for the very short period in June, when a diet was used having Robinson's Patent Groats as its basis.

35 K.A. units. Urine chromatography revealed several unidentified amino acids but galactose was absent. During this period weight gain was only $10 \mathrm{oz}$. and attempts to increase this by adding arachis oil to the full strength food were unsuccessful.

On May 3 (aged 11 weeks) generalized convulsions recurred, and became increasingly frequent. They were unaffected by phenobarbitone gr. $\frac{1}{8}(8 \mathrm{mg}$.) b.d., but their frequency was decreased by giving $2 \mathrm{oz}$. of isotonic glucose-saline solution between the four-hourly feeds of L.L. Milk Food. Unfortunately on this regime the baby gradually lost weight, despite adequate fluid and calorie intake, and weighed only $7 \mathrm{lb} .2 \mathrm{oz}$. at the age of 12 weeks. To try and increase weight larger quantities of L.L. Milk Food were given more frequently; although there was an immediate weight gain, fits became increasingly frequent over the next four days, occurring about 30 minutes after starting each feed. Estimations of the blood electrolytes and serum calcium were within normal limits, but the non-fermentable blood sugar was high. The fits were thought to be due to galactose-induced hypoglycaemia and to prevent this one drachm of sugar was added to each feed. The incidence of fits was reduced but diarrhoea again became troublesome, and on the third day of this regime she lost $10 \frac{1}{2} \mathrm{oz}$. in 24 hours. Gram negative organisms and streptococci were present in the stools and treatment with intravenous fluids, including blood, and oral chloramphenicol, was given. Feeding with oral crystalloids and Casilan was slowly re-introduced. To prevent hypoglycaemia feeding with Casilan in 5\% dextrose was tried, but a further severe attack of diarrhoea and dehydration required treatment with intravenous fluids. Feeding with Casilan and 5\% dextrose was again slowly re-introduced, but on this regime she slowly lost weight and at the age of 14 weeks weighed only $6 \mathrm{lb} .10 \mathrm{oz}$. At this stage she refused her Casilan feeds, but it is 
significant that during the whole period of critical illness since L.L. Milk Food was discontinued no fits occurred. However, it was reluctantly decided to try again with L.L. Milk Food mixed in $5 \%$ dextrose, but the fits again recurred, although she maintained her weight. On June 3 (age 15 weeks), a one-third strength modified Moll's diet (using Robinson's Patent Groats) was tried. She took the food well for 12 hours but after a total of only $12 \mathrm{oz}$. of the mixture she became completely comatose, with a general flaccid paralysis, and loss of all reflexes. Her liver had increased in size to three inches below the right costal margin. The level of non-fermentable blood sugar was over $300 \mathrm{mg} . / 100 \mathrm{ml}$. Intragastric tube feeding with a glucose solution of $1.75 \mathrm{~g} . / \mathrm{kg}$. body weight was given, and the corneal and cough reflexes returned. Intragastric feeding with a solution containing $3.5 \mathrm{~g}$. glucose $/ \mathrm{kg}$. body weight, $3 \mathrm{oz}$. three-hourly, was given for 18 hours by which time spontaneous movements had returned, and feeding with oral crystalloids could be commenced. It is quite remarkable that within 24 hours of stopping this modified form of Moll's diet the liver was enlarged to only half an inch below the right costal margin.

Feeding with L.L. Milk Food and glucose solution $(3.5 \mathrm{~g} . / \mathrm{kg}$.) was recommenced and although she gained $7 \mathrm{oz}$. in weight over the next two weeks the liver steadily increased in size, and the fits, always related to feeds, became more troublesome. A period of twitching lasting 60 minutes was finally terminated by intragastric tube feeding with the glucose solution.

On June 15 (age 17 weeks) a further modification of Moll's diet using a proprietary rice flour (Robinson's Baby Rice) in a 1 in 4 dilution, alternating with oral crystalloids, was commenced. A further attack of diarrhoea occurred after two days and the diet was temporarily replaced by oral electrolyte solutions. The Moll's diet was recommenced and over the next few days there was a marked improvement in her well-being: spontaneous activity increased, the monilia infection of the mouth healed, and she had less frequent bowel movements. During the next two weeks concentration of the Moll's diet was slowly increased to full strength, by which time (age 20 weeks) she weighed $6 \mathrm{lb} .10 \mathrm{oz}$. She was lively and took her feeds well. She cried lustily for the first time; the liver was palpable half an inch below the costal margin and the spleen was just tipped. In the first month of the full strength regime, she gained $3 \mathrm{lb}$., her mental and physical development showing similar improvement.

Weaning on to a lactose free selection of proprietary strained foods was commenced without incident at the age of 7 months.

An aqueous multivitamin solution (Abidec) $0.3 \mathrm{ml}$. daily was given throughout the illness, and the use of ferric ammonium citrate mixture for infants B.P.C. (30 minims t.d.s.) produced satisfactory increase in the haemoglobin.

Now at the age of 9 months she weighs $17 \mathrm{lb} .14 \mathrm{oz}$., and mental development corresponds approximately to that of a 7-month-old normal infant. The spleen is still palpable, but the liver is not enlarged and there are no cataracts. There are no urinary abnormalities, and the haemoglobin is $85 \%(12.7 \mathrm{~g}$.).

The patient's brother (aged 3 years) excreted small amounts of galactose in the urine during a galactose tolerance test, but did not otherwise show any features of the disease. Normal results were obtained in the parents.

\section{Discussion}

This case illustrates the harmful effect of even small amounts of lactose in the diet of infants with galactosaemia. This may be due to the accumulation of galactose-1-phosphate in cells (Schwarz, Golberg, Komrower and Holzel, 1956), and indirectly to the production of hypoglycaemia.

Depression of blood glucose was found by Mason and Turner (1935) during galactose tolerance tests, and irreversible hypoglycaemia may follow them (Townsend, Mason and Strong, 1951). Several authors (Goldbloom and Brickman, 1946; Komrower, Schwarz, Holzel and Golberg, 1956) have also drawn attention to the depression of blood glucose in patients taking milk-containing foods, and, although unable to relate this to any specific symptoms, considered that it contributed to the impairment of cell metabolism. Cox and Pugh (1954) recorded convulsions in a child taking a halfcream dried milk whilst Clay and Potter (1955) in an infant receiving a diet containing Casilan found that the fits stopped when mixed feeding was introduced and suggested that a metabolic cause was responsible for them.

That the metabolic disorder underlying convulsions is the recurrent depression of blood glucose is suggested in the present case by the relationship of convulsions to feeding times, their increasing frequency as lactose containing foods were continued and their cessation following the complete exclusion of lactose. The failure of phenobarbitone to control the convulsions, whilst dextrose in high concentration reduced their incidence, together with the associated high level of non-fermentable blood sugar at the time of fits, also tend to support this. Hypoglycaemia may follow the ingestion of galactose because it is more rapidly absorbed than glucose and also tends to inhibit glucose absorption (Goldbloom and Brickman, 1946) and this may account for the occurrence of fits at meal times in the present case.

It follows that the complete exclusion of lactose from the diet in infancy should be the aim in all cases of galactosaemia; in the severer forms it is life saving, and it is suggested that it is no less important in milder cases. Mental deficiency and cataracts may follow an initial improvement with diets containing small amounts of lactose (Cox and Pugh, 1954), and these complications may be preventable. 
Several diets have been recommended for the treatment of galactosaemia but some of them proved unsatisfactory for a variety of reasons. Malt and soya mixtures are lactose free and there have been several reports of their use (Townsend et al., 1951; Bennett, 1958). Unfortunately, they may produce diarrhoea, as in this case. It has been suggested that this is caused by the high dextrose content and that half strength mixtures may not have this effect (Wokes, 1958). The preparation Nutramigen has been widely used in the United States with good results (Bruck and Rapoport, 1945; Isselbacher, 1957); it does, however, contain small amounts of lactose (Holzel et al., 1957).

Mixtures containing Casilan have been frequently used, but are known to contain $1 \%$ lactose (Cox and Pugh, 1954; Clay and Potter, 1955). In this case improvement in jaundice followed its use, but there was little change in the weight or hepatomegaly.

L.L. Milk Food (Cow and Gate) has been recommended (The Hospital for Sick Children, 1958) and is said by the makers to contain less than $0.1 \%$ of lactose. In addition to the occurrence of convulsions in our patient, weight gain did not occur and there was again no change in liver size.

A diet was introduced by Moll and Stransky in 1922 for the treatment of chronic feeding disorders in children, permitting the exclusion of milk without restriction of calories. The basis of this diet is a milk free cereal, Moll and Stransky used biscuit flour, and egg. Holzel (1954) was first to use a modified form of this diet in cases of galactosaemia, using the cereal Farex (Glaxo) as the base (Holzel, 1954; Komrower et al., 1956; Schwarz, Holzel and Komrower, 1958). This cereal now contains approximately $2.5 \%$ of lactose (Furnivall, 1958). Robinson's Patent Groats (J. and S. Coleman, Ltd.) have also been used (Holzel, Komrower and Schwarz, 1955); a mixture containing this cereal was used for only a short time in this case and was followed by a comatose state. Although there was strong evidence in favour of this being caused by its lactose content, none was found on testing the cereal using the phenylhydrazine reaction. The use of rice flour, which is lactose free, as the main ingredient for Moll's diet was recommended by Holzel et al. (1957), and this was the only diet found to be completely satisfactory in this case. Rapid improvement in general health, freedom from infection and reduction in liver size were followed by gain in weight. It is significant that no more fits have occurred, and although it is at present early to assess mental development satisfactorily, this appears to be progressing well. The use of this diet at an early age would probably avoid the necessity of intra- venous therapy and blood transfusions which were essential in this case. A recipe for the diet used is given in the appendix below. Once mixed feeding is begun, the exclusion of lactose becomes somewhat simpler; tinned strained foods are widely used in weaning and a short list of suitable lactose free varieties is given in the appendix.

Some antibiotic suspensions commonly used in infants were tested for lactose by the phenylhydrazine method: suspensions of penicillin ' $V$ ' (Distaquaine ' $V$ ', The Distillers Company) and tetracycline (Achromycin, Lederle) were found to contain lactose, but chloramphenicol (Chloromycetin, Parke Davis) did not. It is suggested that where an oral antibiotic is indicated, this is the most suitable in cases of galactosaemia.

\section{Summary}

A case of severe galactosaemia in a newborn baby is described, with especial reference to the treatment. The various diets which have been recommended are reviewed; from their use in this case it is concluded that a completely lactose free diet is essential. A suitable form of treatment is described.

We express our thanks to Major S. M. Jarvis, R.A.M.C., for his constant advice and help, and to Mrs. K. Parnaby for help with the diet. It is a pleasure to record the never failing co-operation of the nursing and laboratory staff of this Hospital.

\section{REFERENCES}

Andersen, D. H. (1957). In Biochemical Disorders in Human Disease, ed. R. H. S. Thompson and E. J King, p. 695. Churchill, London.

Bennett, C. E. (1958). U.S. armed Forces med. J., 9, 112.

Bergren, W. R., Donnell, G. and Kalckar, H. M. (1958). Lancet, 1, 267.

Bruck, E. and Rapoport, J. (1945). Amer. J. Dis. Child., 70, 267.

Bruck, E. and Rapoport, J. (1945). Amer. J. Dis. Child., 70, 267.
Clay, P. R. and Potter, C. T. (1955). Arch. Dis. Childh., 30, 147.

Cox, P. J. N. and Pugh, R. J. P. (1954). Brit. med. J., 1, 613.

Furnivall, M. (1958), Lancet, 1, 163.

Goldbloom, A. and Brickman, H. F. (1946). J. Pediat., 28, 674.

Holzel, A. (1954). Med. Ill., 8, 44.

— and Komrower, G. M. (1955). Arch. Dis. Childh., 30, 155.

- - - and Schwarz, V. (1955). Lancet, $2,92$.

Isselbacher, K. J. (1957). Amer. J. Med., 22, 703.

Komrower, G. M., Schwarz, V, Holzel, A. and Golberg, L. (1956). Arch. Dis. Childh., 31, 254.

Mason, H. H. and Turner, M. E. (1935). Amer. J. Dis. Chịld., 50. 359.

Moll, L.. and Stransky, E (1922). Jb. Kinderheilk., 100, 3.

National Institutes of Health (1957). Clinical Staff Conference on Galactosaemia. Ann. intern. Med., 46, 773.

Schwarz, V., Golberg, L., Komrower, G. M. and Holzel, A. (1956) Biochem. J., 62, 34.

- Holzel, A. and Komrower, G. M. (1958). Lancet, 1. 24.

Tattersall, G. (1958). Personal communication.

The Hospital for Sick Children (1958). Diets for Sick Children. 3rd ed., p. 16. London.

Townsend, E. H., Mason, H. H. and Strong, P. S. (1951). Pediatrics 7, 760 .

Wokes, F. (1958). Personal communication.

\section{APPENDIX}

\section{Suitable Foods Used in this Case}

Modified Form of Moll's Diet. $6 \mathrm{oz}$. of Robinson's Baby Rice are mixed with $14 \mathrm{oz}$. of water. Two egg yolks are beaten with $3 \mathrm{oz}$. of glucose and added to this mixture. 
Two egg whites, a pinch of salt and a pinch of bicarbonate of soda are finally added and the mixture is put in a dish greased with margarine and heated for half an hour in a saucepan of boiling water. The resulting pudding is diluted with equal parts of boiled water to make up the feeds. A more dilute form should be used initially.
List of Tinned Strained Goods (Heinz). Carrots, green beans, beef and liver soup, beef broth with beef and barley, bone and vegetable broth, apples and apricots with rice. Although peas are lactose free, they contain stachyose and paragalacto-araban which are metabolized to galactose (Tattersall, 1958). 